\title{
$\angle S$ Research Suare \\ Is Suicide of Older Adults With Dementia \\ Preventable? Evaluation of the Effect of Long-term \\ Care Insurance System
}

\section{Sungje Moon}

Korean Medical Association

Mankyu Choi

Korea University

Minsung Sohn ( $\square$ minsinge@cuk.edu )

Department of Health and Care Administration, The Cyber University of Korea, Seoul, South Korea

\section{Research Article}

Keywords: Dementia, Long-term care insurance, Survival analysis, Suicide, Older adults

Posted Date: January 22nd, 2021

DOl: https://doi.org/10.21203/rs.3.rs-148862/v1

License: (c) (i) This work is licensed under a Creative Commons Attribution 4.0 International License.

Read Full License 


\section{Abstract}

Background: South Korea has the highest older adults' suicide rate in the world. This study proposed a multifaceted policy to reduce the suicide risk among older adults with dementia by evaluating the effectiveness of the expanded long-term care insurance coverage.

Methods: About 62,282 older adults with dementia were selected as study samples from the National Health Insurance Service's "Older Adults Cohort DB (2002 to 2015)." This study confirmed how the demographic characteristics, health status, and the long-term care services (LTCS) of older adults with dementia affect their suicide. Data analysis was conducted with the Kaplan-Meier, Cox-regression to represent the yearly survival curve from 2002 to 2015, and the suicide rate was identified by demographic characteristics, health status, and policy. Also, difference-in-differences (DID) estimation was conducted to analyze the effect of LTCS on suicide rates by comparing statuses before and after 2014.

Results: The results revealed statistically significant differences in sex, activities of daily living, cognitive ability, caregivers, and use of LTCS (Log-rank test $p<0.001$ ). The suicide risk of older adults using LTCS was about 0.256 times lower than those who did not use it $(p<.001)$, after adjusting controls. Regarding the policy effect of LTCS, their suicide rate increased after the expansion of dementia grade $(\mathrm{OR}=2.131$, $95 \% \mathrm{Cl}=1.061-4.280)$ but was still lower among LTCS users than non-users $(\mathrm{OR}=0.296,95 \% \mathrm{Cl}=0.183$ 0.478). The interaction term indicating whether older adults with dementia use LTCS after the expansion of dementia grade was not statistically significant.

Conclusions: This study not only identified differences in suicide rates depending on the sex, ADL, and type of caregiver at the individual level, but also confirmed that national policies and long-term care services could protect their lives. It highlights the importance of national level management to prevent suicide among older adults with dementia and offers effective policy suggestions.

\section{Background}

Although average life expectancy is increasing worldwide, extreme social problems such as committing suicide are occurring due to various causes. In other words, it is a serious public health concern. A prolonged lifespan does not necessarily imply an improved quality of life. In 2017, the average of the agestandardized suicide rates of Organisation for Economic Co-operation and Development (OECD) countries was 11.2 per 100,000 people, while that of South Korea was the highest at 24.6 [1]. South Korea's rate is more than twice the average of OECD countries, indicating that the suicide problem is at its most critical level here. Particularly, the suicide rate among older adults in South Korea is the leading problem among OECD countries [2]. The ratio of older adult suicide to total suicide incidence was over $70 \%$ in South Korea, while the average of OECD countries was about $22 \%$. Additionally, it was remarkably higher than in other age groups by about 13 times $[2,3]$. These indicators represent a necessity to examine not only the medical problems of aging but also the acute public health and sociological problems that older adults face. 
Dementia is a condition in which memory or cognitive functioning deteriorates and progressively interferes with daily life [4]. The number of dementia patients worldwide is expected to increase from about 50 million todays to 152 million in 2050 [5]. Consequently, dementia will become one of the world's highest priorities and an important public health concern. In South Korea, the number of patients with dementia was about 710,000 in 2017 , and 3.6 times higher than in 2007 . More than $90 \%$ of dementia patients were older adults aged above 65 years [6]. Therefore, considering the rapidly increasing older adult population, the increasing number of older adults with dementia will become a national concern. Additionally, dementia also increases suicide risk. It was found that the risk of suicide increased with the progress of the disease as the patients feared increasing physical and mental decline and thought that it would impose an emotional and economic burden on their families [7]. Besides, it also causes depression anxiety symptoms, suicide thought, and self-harm in the caregivers, including family and neighbors $[8,9]$. Therefore, dementia is a pressing concern that requires constant monitoring, prevention, and management in various aspects, and continuous research to find preventive solutions to social problems such as suicide.

Several studies have verified the relationship between dementia and suicide at the individual level. According to the interpersonal theory of suicidal behavior, the most dangerous aspect of suicidal desire is the coexistence of both a thwarted belongingness, i.e., feeling disconnected from a social relationship, and a perceived burdensomeness, i.e., perceiving oneself as a burden to others [10]. Patients with dementia feel alienated from social events and conversations concerning family or friends, and think that they are not helpful or are burdensome to others due to their memory loss [11]. In other words, dementia patients are a vulnerable group exposed to suicidal thoughts and risks due to worries about the disease characteristics. The Suicide Prevention Research Center at the University of Aarhus in Denmark conducted a follow-up study on suicide among older adults for a period of 11 years beginning 1990. It found that the largest number of older adults committed suicide after being diagnosed with dementia. Older adults with dementia aged above 70 years were found to have a three times higher suicide risk than older adults without dementia [12]. Additionally, older adults with dementia had double hospitalization rates due to self-harm compared to the rest. Mortality, re-admission, and hospitalization period within 12 months after admission was also higher for this group [13]. Among the older adults who committed suicide due to dementia, overall suicide attempts and suicide rates were higher among mild dementia patients recently diagnosed with dementia $[7,12,14]$. Similarly, suicide attempts among mild dementia patients were higher than among older adults with light cognitive impairment [15-17]. Nevertheless, the studies on suicide among older adults with dementia mainly considered socioeconomic factors at the individual level and were limited in presenting specific guidelines for prevention at the national level. Since dementia is hard to curable and rarely achieves full recovery unlike other diseases, institutional help, such as early detection and management of disease, is essential to lower the suicide rate.

According to the World Health Organization (WHO), suicide is a representative preventable death, which can be prevented through appropriate national intervention and management. It is also reported as a death that can be avoided through effective health policy and medical services [18]. As a strategy to respond to suicide risk factors, steps should be taken to improve medical accessibility and mental health 
for all citizens, along with selective prevention and follow-up for suicide-vulnerable groups outside the community's help. In a report titled "Development of National Strategies for Suicide Prevention," the United Nations and WHO recommended that the government pay attention to suicidal behavior, and emphasized comprehensive policies including social solidarity and responsibility. Dementia, which is a high-risk factor for suicide, causes double suffering in both patients and families, and therefore, the government needs to alleviate the pain and burden of the patient and their family by expanding dementia management policy and the social safety net.

The "National Responsibility Plan for Dementia" was announced in South Korea to reduce the out-ofpocket costs rate to $10 \%$ for severe dementia patients. A "Dementia special grade" was established in the long-term care insurance (LTCl) system in 2017. Additionally, the expansion of day and night shelters for dementia patients improved accessibility, relieved the burden of care for mild dementia patients, and improved their quality of life. These policies aimed to protect the family's economic and caring burden from dementia and social problems such as suicide. Previous studies that conducted suicide prevention programs for older adults with mild dementia in South Korea, who received day care centers services, reported an effect on their subjective health level, depression, and suicidal intentions [19]. Additionally, nursing home admission was found to lower suicide risk among older adults with dementia aged above 60 years [7].

According to the results of a study conducted on 634 older adults with dementia for 7 years, about $10 \%$ of the older adults responded that they had thought of suicide [20]. Nevertheless, previous studies have mainly focused on the caregivers of dementia patients, such as their depression, stress, and murderous behaviors or impulses $[8,21]$. Older adults with dementia also have the right to end their lives, even though they may not be able to recognize their suffering because of difficulty of expression. Therefore, this study emphasizes national-level policies to protect older adults with dementia and suggests the direction of suicide prevention strategies.

At the national level of prevention, it might be necessary to approach the vulnerable targets that are more exposed to the risk and environmental factors of suicide. Additionally, we need to devise measures that can prevent suicide through appropriate, timely and institutional help. Therefore, this study has evaluated whether the national approach through the LTCS system can prevent suicide among older adults with dementia and proposes a comprehensive three-pronged plan to prevent suicide. First, the status of suicide by risk factor for Korean older adults with dementia was identified. Second, the effect of using LTCS on suicide among older adults with dementia was determined. Lastly, by evaluating the effectiveness of policies, such as the introduction of long-term care insurance and the expansion of the dementia grade, we proposed a multifaceted policy to reduce the suicide problem of older adults with dementia.

\section{Materials And Methods}

\section{Research Design and Participants}


In 2002, the National Health Insurance Service (NHIS) in South Korea established the "National Health Information Database (NHI DB)" that includes information of patients' medical records, disease history, and prescriptions for health insurance and medical aid beneficiaries. The DB was systematically sampled and stratified by sex, age, region, and the level of insurance cost to ensure representativeness. Additionally, the NHIS DB is divided into "Standard Cohort," "Health Examination Cohort," "Older Adults Cohort," and "Infant Cohort" DB to study specific populations.

This study used a total of 14 years of "Older Adults Cohort DB" from 2002 to 2015 . The full DB includes randomly extracted 558,147 people, who were about $10 \%$ of the total 5.5 million population of Korean older adults aged over 60 in December 2002. To classify the older adults with dementia as the study sample, we selected 121,235 older adults who were outpatient or inpatient at least once with disease code related to dementia (F00-F03, KCD). The final sample included 62,282 older adults, after excluding individuals with missing values in the main variables used in the analysis.

Figure 1 presents the structure of the selected study sample. First, among the older adults who survived until the end of follow-up, Case 1 was an older adult who had been diagnosed with dementia from the beginning of the observation, while Case 2 was an older adult who had been diagnosed with dementia during the observation. Second, Cases $3 \& 4$ had the same criteria for diagnostic period of dementia as Cases 1 \& 2; however, the difference was whether the older adult had died before the end of follow-up.

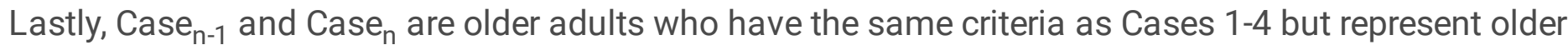
adults who have used services under the long-term care insurance system since its introduction.

\section{Measures}

\section{Dependent Variable: Suicide}

Suicide is the dependent variable in this study, to verify whether the cause of death data included the suicide codes (X60-X84). The binary variable was coded as 1 if the older adult committed suicide and 0 otherwise.

\section{Independent variables: Demographic Characteristics and Health Status}

The independent variables in this study included the demographic characteristics of older adults with dementia, i.e., sex, age, income level, and caregivers and their health status. Sex comprised male and female, and ages were classified into three categories of 60-69 years, 70-80 years, and above 80 years. For the income level, a dummy variable was used which re-categorized the national classification of $10^{\text {th }}$ quantile into $5^{\text {th }}$ quantile; the $1^{\text {st }}$ quantile (medical beneficiaries), $2^{\text {nd }}$ quantile (the $1^{\text {st }}-2^{\text {nd }}$ quantile, which is the lowest income level), $3^{\text {rd }}$ quintile $\left(3^{\text {rd }}-5^{\text {th }}\right), 4^{\text {th }}$ quintile $\left(6^{\text {th }}-8^{\text {th }}\right)$, and $5^{\text {th }}$ quintile $\left(9^{\text {th }}-10^{\text {th }}\right)$. The type of caregiver was categorized as no caregivers, family and neighbors, and nurses. The health status included activities of daily living ( $A D L)$ and cognitive ability. The ADL was classified into three categories (independent, partially dependent, and fully dependent) by using the total scores of 13 questions consisting of four responses (full independence, incomplete independence, partial dependence, and full 
dependence). For cognitive ability, the binary variable was divided into "good" and "bad" using the total scores of 10 questions.

\section{Policy Variable: Long-Term Care Services}

This study used the experience of using LTCS as a policy variable, and the effect of LTCS on preventing suicide was confirmed for the older adults with dementia. The LTCS types were classified into non-user, facility benefits, and in-home benefits. Generally, the facility services are used when the disease symptoms are severe. Therefore, the service type was classified as a facility service if the older adult used both facilities and in-home services.

\section{Analysis Strategy}

The following analysis methods were used. First, the factors affecting suicide among the older adults with dementia were identified. Second, the Kaplan-Meier and Cox regression analysis were conducted to represent the yearly survival curve from 2002 to 2015, and the suicide rate was identified by demographic characteristics, health status, and policy. Third, to confirm the effect of reinforcing the insurance coverage with the expansion of LTCS's "dementia special grade," the difference-in-differences (DID) estimation was conducted to analyze the effect of LTCS on suicide rates by comparing statuses before and after 2014 .

\section{Results}

\section{Risk Factors Influencing Suicide Among the Older Adults with Dementia}

Table 1 shows the results of a chi-square test performed to compare the difference in suicidal death rate according to the general characteristics of older adults with dementia. Males $(0.33 \%)$ had more than twice the frequency of committing suicide than females $(0.14 \%)$, and the suicide rate by age was highest in the $60 \mathrm{~s}(0.41 \%)$, followed by the $70 \mathrm{~s}(0.21 \%)$, and the above-80s $(0.15 \%)$. Concerning $A D L$, suicide frequency was the highest in those who were independent $(0.3 \%)$, and the lowest in fully dependent older adults $(0.05 \%)$. Additionally, older adults with good cognitive ability $(0.27 \%)$ had a higher suicide frequency than those with poor cognitive ability $(0.11 \%)$. Considering the type of caregiver, older adults with no caregiver had the highest suicide frequency $(0.35 \%)$, followed by family or neighbors $(0.23 \%)$ and nurses $(0.1 \%)$. Lastly, LTCS non-users $(0.33 \%)$ had a higher suicide frequency than users, and in-home service users $(0.23 \%)$ had a higher suicide frequency than facility service $(0.06 \%)$ users. The difference in suicide frequency according to income level was not statistically significant.

\section{Survival Curves by Risk Factors of Older Adults with Dementia}

Figure 2 shows the results of the Kaplan-Meier Survival Curve to estimate the survival rate within 14 years for each section according to the demographic characteristics, health status, and use of long-term care services. As a result of estimating survival rates, statistically significant differences were found in sex, $A D L$, cognitive ability, caregivers, and use of LTCS (Log-rank test $p<0.001)$. On the other hand, there was no difference in survival rate by suicide according to age ( $p=.673)$ and income level $(p=.883)$. 


\section{Factors Affecting Suicide Among Older Adults with Dementia}

Using the Cox proportional hazard model, this study confirmed the hazard ratio of suicide according to the type of LTCS used by older adults with dementia. Table 2 shows the analysis results.

Model 1 is the result of analyzing the suicide hazard ratio according to the type of LTCS without adjusting the control variables. Compared to the older adults who did not use LTCS, the suicide rate of those using facility services was about 0.628 times lower $(p=.017)$, and the suicide rate of those using in-home services was about 0.151 times lower $(p<.001)$.

Model 2 is the result of adjusting control variables for the suicide hazard ratio according to LTCS types. The hazard ratio of each control variables on suicide was also verified. As a result of adjusting demographic characteristics and health status, the suicide risk of older adults with dementia who used facility service was about 0.256 times lower than those who did not use LTCS $(p<.001)$. However, the effect of in-home service on suicide risk was not statistically significant. In control variables, the hazard ratio according to sex and ADL was significant. The suicide hazard ratio of women was 0.397 times lower than of men $(p<0.001)$, and the hazard ratio of fully dependent older adults with dementia was 0.29 times lower than of independent older adults $(p<0.001)$.

\section{Policy Effects of Long-Term Care Services on Suicide of Older Adults with Dementia}

Table 3 shows the results of the difference-in-differences (DID) analysis performed to compare the policy effects of the LTCS's "dementia grade expansion" on suicide rate of older adults with dementia. The suicide rate of older adults with dementia increased in the period after the expansion of dementia grade compared to before the change $(\mathrm{OR}=2.131,95 \% \mathrm{Cl}=1.061-4.280, p=.034)$. However, it was lower among LTCS users than non-users (OR=0.296, 95\% $\mathrm{Cl}=0.183-0.478, p<.001)$. The interaction term indicating whether older adults with dementia used LTCS after the expansion of dementia grade was not statistically significant.

\section{Discussion}

In general, people with dementia assume that it is difficult to attempt suicide due to cognitive impairment, but nonetheless, suicide of dementia patients often occur in many countries, including South Korea. Therefore, social problem of suicide among dementia patients should receive greater attention, and adequate assessment of suicidal ideation, attempts and psychological and physical support for patients with dementia are needed.

In South Korea, as the total older adults' population increases, suicide is becoming a serious social concern that can no longer be overlooked because of worlds' highest suicide rate in older population. However, there is still a lack of systematic research on suicide among older adults with dementia. Thus, this study evaluated whether the national intervention measure of LTCS has the effect of preventing suicide among older adults with dementia in the context of a continuously aging population and the 
rapidly increasing mortality rate of older adults with dementia. Despite Korea's high and growing suicide rate among people with dementia, there is a lack of empirical research on the suicide. This study analyzed 558,147 older adults from the total population of individuals aged over 60 years in Korea through random sampling using the "Older Adults cohort DB" of 14 years from 2002 to 2015.

The study found that, first, at the individual level, men had a higher suicide rate than women, and the suicide rate among older adults with dementia was higher when their $A D L$ and cognitive functioning were mild rather than severe. Additionally, the suicide rate was the highest if there were no caregivers to help them with daily living. The suicide rate was also higher if family members or acquaintances cared for them instead of professional caregivers.

Regarding ADL and cognitive functioning, the suicide rate among older adults with dementia was higher when their $A D L$ and cognitive functioning were mild rather than severe. This is consistent with recent studies showing that older adults diagnosed with dementia most recently are more likely to attempt suicide [7, 12, 14-17]. In Korea, a study assessing the effects of "suicide prevention programs" on older adults with mild dementia showed positive effects as time changed due to perceived health conditions, social support, depression, and suicidal intentions [19]. A Canadian study reported that a positive social relationship alone could reduce the intentional self-harm among long-stay home care clients aged over 60 years [22]. Therefore, it is essential to provide interventions for older adults to prevent the risk of suicide among older adults with mild dementia or provide health education and rehabilitation programs for mental health management [23]. Also, to them, non-pharmacological strategy such as multicomponent training may be an important to enhance ADL's functionality on older adults with dementia [24]. Efforts should be aimed at providing customized services that can improve problem behavior to the extent that older adults can be active but without branding them as such. Recently, the Korean government is also making efforts to invest in the LTC facility resources and established a long-term care plan for placement of professionals for customized services.

Regarding the caregivers of older adults with dementia, the risk of suicide rate was lower when professional caregivers were used rather than family members or acquaintances. We can infer the reason for this from the literature that the burden and stress increases when taking care of family members or close neighbors. In Korea, there are several cases of older adults suffering from dementia committing suicide in the early stages because of the inability to overcome the mental distress of being a burden on the family [25]. Self-care needs and behaviors of caregivers including ample sleep, social engagement and support, and leisure activities are also essential for health care in patients with dementia [26, 27]. This can also have a positive effect on the formation of a relationship between the two groups. Systematic support for the formation of a relationship between dementia patients and family caregivers can have a positive effect not only on the patients but also on family caregivers [28]. It may also result from problems with the caregiver's expertise as well as the burden of support for family or acquaintances. Therefore, it is essential to develop a "specialized curriculum" focused on staff delivery standards and mandatory training for unskilled nurses, as in Japan, to provide standardized services and establish infrastructure for ascertaining the role of caregivers $[29,30]$. Besides, older adults with dementia and their 
caregivers can expect targeted improvements such as clinical knowledge of disease, better communication between dementia patients and service providers, and more proactive care plans through systematic counseling and education for an acknowledge cognitive decline [31].

Second, as a result of examining the effects of LTCS intervention at the national level, the suicide rate of non-users was higher than that of LTCS users. Among users, the suicide rate of home-service users was higher than that of facility service users. In other words, long-term care services provided by the government had a positive effect on the prevention of suicide among older adults with dementia. This is consistent with previous studies indicating that the effects of the national system or community program could contribute to the mental health of dementia patients [32,33]. Older people also experience depression as they age and feel isolated, especially when they have feelings of perceived burdensomeness to others $[10,11]$. Thus, they had a lower suicide rate when they were protected in a facility and served in a space where communication with people around them was relatively high.

Additionally, an analysis of the effects of the long-term care insurance system for older adults with dementia showed that the suicide rate among users was significantly lower than that of non-users, depending on the use of the service, while the suicide rate was higher after the expansion of the LTCS grade (after 2014) compared to before the expansion (before 2014). Therefore, the interaction between before and after the expansion of the grading and whether the LTCS was used showed no significant results.

In other words, the use of LTCS has a positive effect on lowering the suicide rate among older adults with dementia. Therefore, the country's policy direction to increase access to long-term care services might be the precise direction. Furthermore, efforts are required to establish various programs and a care service culture within the LTCl system as well as quantitative increase in nursing facilities to prevent suicide among older adults with dementia. Additionally, it is necessary to develop measures to ensure continuous management and protection by recognizing problems with long-term care home service and establishing monitoring systems in-home by utilizing the apps and chatbots that have recently emerged. The LTCI system for older adults has increased the accessibility of services for older adults with dementia by implementing the expansion of the dementia grade since 2014; however, any change in the suicide rate was not observed in this study. This may be caused by an increase in the number of older patients with dementia who entered the system in the early stages of enhanced system security. Moreover, there may be limitations in observing the system for a short period of time; therefore, continuous monitoring and research is needed to develop measures to prevent and manage dementia patients in the future.

This study has several implications. First, this study is meaningful as it is the first empirical study on suicide among older adults with dementia in South Korea. Additionally, data from the NHIS's representative "Older Adults cohort DB" were used for about 14 years from 2002 to 2015, enabling comparative analysis between before and after the extension of the dementia grade in 2014. Therefore, this study is advantageous as an observation of long-term changes as a longitudinal study and effective in identifying causal relationships between exposure and outcome in the empirical analysis. Second, the 
study recognized the importance of management at the national level for the prevention of suicide among older adults with dementia and makes effective policy suggestions such as linking the LTCI system with the suicide prevention program.

However, in this study, the effect of enhancing the coverage of "expanding the dementia grading" of LTCI was limited to a short-term observation of only two years. Further research should make a continuous assessment of the plan from a long-term perspective. Nevertheless, the LTCS strengthened the accessibility of the service to older adults with dementia and evaluated the effect of contributing to the prevention of suicide by providing care services, thereby identifying the direction of policy effects. Given that the current system has entered its sixth year since the expansion of the dementia grading, it is meaningful that the results of this study can be provided as basic data to establish a national long-term plan for LTCl, which legally establishes a basic plan for every five years.

\section{Declarations}

\section{Ethics approval and consent to participate}

KUIRB-2018-0014-01

\section{Consent for publication}

Not applicable.

\section{Availability of data and materials}

The data that support the findings of this study are available from from Older Adults Cohort DB (2002 to 2015) for the longitudinal study of aging by the National Health Insurance Service. Restrictions apply to the availability of this data, which was used under license for the current study, and so is not publicly available. However, the data can be available for a fee if the author receives permission from the National Health Insurance Service following the IRB approval.

\section{Competing interests}

The Authors declare that there is no conflict of interest.

\section{Funding}

This work was supported by the Ministry of Education of the Republic of Korea and the National Research Foundation of Korea (NRF-2018S1A5A8028924).

\section{Authors' contributions}

Sungje Moon: Writing- Original draft preparation, Methodology, Data curation, Visualization. Mankyu Choi: Writing- Reviewing and Editing, Supervision. Minsung Sohn: Conceptualization, Writing- Original 
draft preparation, Supervision

\section{Acknowledgements}

This research received ethics approval from Korea University.

\section{References}

1. OECD. Health at a Glance 2019. 2019.

2. OECD. Society at a Glance 2019. 2019.

3. Kanwal S, Perveen S, Sumbla Y. Causes and severity of suicide in developed nations of East Asia. JPMA The Journal of the Pakistan Medical Association. 2017;67(10):1588-92.

4. WHO. Towards a dementia plan: a WHO guide. 2018.

5. Prince M, Wimo A, Guerchet M, Ali G, Wu Y, Prina M. World Alzheimer report 2015: the global impact of dementia. London: Alzheimer's Disease International; 2015. Report; 2019.

6. Dementia Nlo. Korean Dementia Status 2018. 2018.

7. Seyfried LS, Kales HC, Ignacio RV, Conwell Y, Valenstein M. Predictors of suicide in patients with dementia. Alzheimer's \& dementia : the journal of the Alzheimer's Association. 2011;7(6):567-73.

8. Joling KJ, O'Dwyer ST, Hertogh C, van Hout HPJ. The occurrence and persistence of thoughts of suicide, self-harm and death in family caregivers of people with dementia: a longitudinal data analysis over 2 years. International journal of geriatric psychiatry. 2018;33(2):263-70.

9. O'Dwyer ST, Moyle W, Zimmer-Gembeck M, De Leo D. Suicidal ideation in family carers of people with dementia. Aging \& mental health. 2016;20(2):222-30.

10. Van Orden KA, Witte TK, Cukrowicz KC, Braithwaite SR, Selby EA, Joiner Jr TEJPr. The interpersonal theory of suicide. 2010;117(2):575.

11. Chen MC, Lin HR. The lived experiences of elderly dementia patients in Taiwan. International journal of mental health nursing. 2019;28(3):784-92.

12. Erlangsen A, Zarit SH, Conwell Y. Hospital-diagnosed dementia and suicide: a longitudinal study using prospective, nationwide register data. The American journal of geriatric psychiatry : official journal of the American Association for Geriatric Psychiatry. 2008;16(3):220-8.

13. Mitchell R, Draper B, Harvey L, Brodaty H, Close J. The survival and characteristics of older people with and without dementia who are hospitalised following intentional self-harm. International journal of geriatric psychiatry. 2017;32(8):892-900.

14. Purandare N, Voshaar RC, Rodway C, Bickley H, Burns A, Kapur N. Suicide in dementia: 9-year national clinical survey in England and Wales. The British journal of psychiatry : the journal of mental science. 2009;194(2):175-80.

15. Borges G, Acosta I, Sosa AL. Suicide ideation, dementia and mental disorders among a community sample of older people in Mexico. International journal of geriatric psychiatry. 2015;30(3):247-55. 
16. Mok E, Lai CK, Wong FL, Wan P. Living with early-stage dementia: the perspective of older Chinese people. Journal of advanced nursing. 2007;59(6):591-600.

17. Osvath P, Kovacs A, Voros V, Fekete S. Risk factors of attempted suicide in the elderly: The role of cognitive impairment. International journal of psychiatry in clinical practice. 2005;9(3):221-5.

18. WHO. Preventing suicide: A global imperative. 2014.

19. Kim J. Development and Evaluation of a Suicide Prevention Program for Elderly with Early Stage Dementia. Kimhae: Inje University. 2015.

20. Koyama A, Fujise N, Matsushita M, Ishikawa T, Hashimoto M, Ikeda M. Suicidal ideation and related factors among dementia patients. Journal of affective disorders. 2015;178:66-70.

21. Anderson JG, Eppes A, O'Dwyer ST. "Like Death is Near": Expressions of Suicidal and Homicidal Ideation in the Blog Posts of Family Caregivers of People with Dementia. Behav Sci (Basel). 2019;9(3).

22. Neufeld E, Hirdes JP, Perlman CM, Rabinowitz T. Risk and protective factors associated with intentional self-harm among older community-residing home care clients in Ontario, Canada. International journal of geriatric psychiatry. 2015;30(10):1032-40.

23. Cations M, May N, Crotty M, Low LF, Clemson L, Whitehead C, et al. Health Professional Perspectives on Rehabilitation for People With Dementia. The Gerontologist. 2020;60(3):503-12.

24. Machado FB, Silva N, Farinatti P, Poton R, Ribeiro Ó, Carvalho J. Effectiveness of Multicomponent Exercise Interventions in Older Adults With Dementia: A Meta-Analysis. The Gerontologist. 2020.

25. DongA-llbo. Continure Suicide of Older Adults with Dementia. Available From https://wwwchosuncom/site/data/html_dir/2012/11/09/2012110900100htmlOnline. 2012.

26. Waligora KJ, Bahouth MN, Han HR. The Self-Care Needs and Behaviors of Dementia Informal Caregivers: A Systematic Review. The Gerontologist. 2019;59(5):e565-e83.

27. Watson B, Tatangelo G, McCabe M. Depression and Anxiety Among Partner and Offspring Carers of People With Dementia: A Systematic Review. The Gerontologist. 2019;59(5):e597-e610.

28. Lee HK, Kim SY. Factors Influencing the Caring Burden of Families with Dementia in a Community. Journal of the Korean Applied Science and Technology. 2019;36(4):1373-84.

29. Ikegami N, Ishibashi T, Amano T. Japan's Long-Term Care Regulations Focused on StructureRationale and Future Prospects. Regulating long-term care quality: An international comparison. 2014:121.

30. Sohn M, O'Campo P, Muntaner C, Chung H, Choi M. Has the long-term care insurance resolved disparities in mortality for older Koreans? examination of service type and income level. Soc Sci Med. 2020;247:112812.

31. Mansfield E, Noble N, Sanson-Fisher R, Mazza D, Bryant J. Primary Care Physicians' Perceived Barriers to Optimal Dementia Care: A Systematic Review. The Gerontologist. 2019;59(6):e697-e708.

32. Telenius EW, Engedal K, Bergland A. Effect of a high-intensity exercise program on physical function and mental health in nursing home residents with dementia: an assessor blinded randomized 
controlled trial. PloS one. 2015;10(5):e0126102.

33. Pan Y, Chen R. The Effect of a Nurse-Led Cognitive Behavioral Protocol on Depressive Symptoms and Coping Strategies of Dementia Caregivers. The journal of nursing research : JNR. 2019;27(6):e55.

\section{Tables}

Table 1. Suicide frequency by general characteristics of the elderly with dementia 


\begin{tabular}{|c|c|c|c|c|c|c|}
\hline \multirow[t]{2}{*}{ Suicide } & & \multicolumn{2}{|c|}{ Yes $^{\dagger}$} & \multicolumn{2}{|l|}{ No } & \multirow[t]{2}{*}{ chi-square } \\
\hline & & $\mathbf{N}$ & $\%$ & $\mathbf{N}$ & $\%$ & \\
\hline \multirow[t]{2}{*}{ Sex } & Male & 56 & 0.33 & 17,083 & 99.67 & \multirow[t]{2}{*}{$22.82^{\star \star \star}$} \\
\hline & Female & 63 & 0.14 & 45,080 & 99.86 & \\
\hline \multirow[t]{3}{*}{ Age } & $60-69$ & 14 & 0.41 & 3,442 & 99.59 & \multirow[t]{3}{*}{$11.16^{\star *}$} \\
\hline & $70-79$ & 55 & 0.21 & 26,220 & 99.79 & \\
\hline & Over 80 & 50 & 0.15 & 32,501 & 99.85 & \\
\hline \multirow[t]{5}{*}{ Income level ${ }^{\mathrm{a}}$} & $5^{\text {th }}$ quantile (Highest) & 37 & 0.18 & 21,096 & 99.82 & \multirow[t]{5}{*}{0.68} \\
\hline & $4^{\text {th }}$ quantile & 25 & 0.19 & 12,860 & 99.81 & \\
\hline & $3^{\text {rd }}$ quantile & 11 & 0.18 & 6,114 & 99.82 & \\
\hline & $2^{\text {nd }}$ quantile & 24 & 0.21 & 11,278 & 99.79 & \\
\hline & $1^{\text {st }}$ quantile (Lowest) & 22 & 0.20 & 10,815 & 99.80 & \\
\hline \multirow[t]{3}{*}{$A D L^{b}$} & Independent & 75 & 0.30 & 24,975 & 99.70 & \multirow[t]{3}{*}{$38.27 \star \star \star$} \\
\hline & Partially dependent & 33 & 0.21 & 15,471 & 99.79 & \\
\hline & Fully dependent & 11 & 0.05 & 21,717 & 99.95 & \\
\hline \multirow[t]{2}{*}{ Cognitive ability ${ }^{c}$} & Good & 86 & 0.27 & 31,371 & 99.73 & \multirow[t]{2}{*}{$22.59 * \star \star$} \\
\hline & Bad & 33 & 0.11 & 30,792 & 99.89 & \\
\hline \multirow[t]{3}{*}{ Caregivers } & None & 14 & 0.35 & 4,001 & 99.65 & \multirow[t]{3}{*}{$17.99 * \star \star$} \\
\hline & Family / Neighbor & 82 & 0.23 & 35,367 & 99.77 & \\
\hline & Nurse & 23 & 0.10 & 22,795 & 99.90 & \\
\hline \multirow[t]{3}{*}{$\operatorname{LTCS}^{d}$} & Non-user & 55 & 0.33 & 16,603 & 99.67 & \multirow[t]{3}{*}{$39.99 * \star \star$} \\
\hline & Facility & 14 & 0.06 & 23,630 & 99.94 & \\
\hline & In-home & 50 & 0.23 & 21,930 & 99.77 & \\
\hline Total & & 119 & 0.19 & 62,163 & 99.81 & \\
\hline
\end{tabular}

The annual average of suicidal mortality rate in the study data is calculated as 25.94 elderly per 100,000 populations. Whereas, Korea's dementia mortality rate in 2015 was 18.6 per 100,000 populations (Statistics Office), but it is estimated that the study sample is likely to be a health risk group as an LTCS applicant among the elderly with dementia. 
ancome level: $1^{\text {st }}$ quantile (Medical aid beneficiaries), $2^{\text {nd }}$ quantile ( 1 st- $3^{\text {rd }}$ quantile), $3^{\text {rd }}$ quantile (4th- $5^{\text {th }}$ quantile), $4^{\text {th }}$ quantile $\left(6^{\text {th }}-8^{\text {th }}\right.$ quantile) $5^{\text {th }}$ quantile $\left(9^{\text {th }}-10^{\text {th }}\right.$ quantile)

${ }^{\text {b} A c t i v i t y ~ D a i l y ~ L i m i t a t i o n: ~ I n d e p e n d e n t ~(s c o r e ~ 13-19), ~ p a r t i a l l y ~ d e p e n d e n t ~(s c o r e ~ 20-26), ~ f u l l y ~ d e p e n d e n t ~}$ (score 27-39)

${ }^{\mathrm{c}}$ Cognitive ability: Good (score 0-5), Bad (score 6-10)

dLTCS: Long-Term Care Service

Table 2. Cox proportional hazard regression for LTCS 


\begin{tabular}{|c|c|c|c|c|c|c|c|}
\hline & & \multicolumn{3}{|c|}{ Model 1} & \multicolumn{3}{|c|}{ Model 2} \\
\hline & & HR & $95 \% \mathrm{Cl}$ & $\begin{array}{l}\mathrm{p}- \\
\text { value }\end{array}$ & HR & $95 \% \mathrm{Cl}$ & $\begin{array}{l}\mathrm{p}- \\
\text { value }\end{array}$ \\
\hline \multirow[t]{3}{*}{ atTCS } & Non-user & 1 & & & 1 & & \\
\hline & Facility & 0.151 & $\begin{array}{l}0.084- \\
0.271\end{array}$ & $<0.001$ & 0.256 & $\begin{array}{l}0.136- \\
0.482\end{array}$ & $<0.001$ \\
\hline & In-home & 0.628 & $\begin{array}{l}0.428- \\
0.921\end{array}$ & 0.017 & 0.732 & $\begin{array}{l}0.487- \\
1.100\end{array}$ & 0.133 \\
\hline \multirow[t]{2}{*}{ Sex } & Male & & & & 1 & & \\
\hline & Female & & & & 0.397 & $\begin{array}{l}0.275- \\
0.574\end{array}$ & $<0.001$ \\
\hline \multirow[t]{3}{*}{ Age } & $60-69$ & & & & 1 & & \\
\hline & $70-79$ & & & & 0.833 & $\begin{array}{l}0.458- \\
1.516\end{array}$ & 0.550 \\
\hline & Over 80 & & & & 0.991 & $\begin{array}{l}0.533- \\
1.843\end{array}$ & 0.978 \\
\hline \multirow{5}{*}{$\begin{array}{l}{ }^{\mathrm{b}} \text { Income } \\
\text { level }\end{array}$} & $5^{\text {th }}$ quantile & & & & 1 & & \\
\hline & $4^{\text {th }}$ quantile & & & & 1.146 & $\begin{array}{l}0.689- \\
1.905\end{array}$ & 0.600 \\
\hline & $3^{\text {rd }}$ quantile & & & & 1.147 & $\begin{array}{l}0.584- \\
2.250\end{array}$ & 0.691 \\
\hline & $2^{\text {nd }}$ quantile & & & & 1.447 & $\begin{array}{l}0.864- \\
2.426\end{array}$ & 0.161 \\
\hline & $1^{\text {st }}$ quantile & & & & 1.167 & $\begin{array}{l}0.675- \\
2.015\end{array}$ & 0.581 \\
\hline \multirow[t]{3}{*}{${ }^{\mathrm{C}} \mathrm{ADL}$} & Independent & & & & 1 & & \\
\hline & $\begin{array}{l}\text { Partially } \\
\text { dependent }\end{array}$ & & & & 0.981 & $\begin{array}{l}0.630- \\
1.528\end{array}$ & 0.933 \\
\hline & Fully dependent & & & & 0.290 & $\begin{array}{l}0.145- \\
0.579\end{array}$ & $<0.001$ \\
\hline \multirow{2}{*}{$\begin{array}{l}{ }^{\mathrm{d}} \text { Cognitive } \\
\text { ability }\end{array}$} & Good & & & & 1 & & \\
\hline & Bad & & & & 0.737 & $\begin{array}{l}0.474- \\
1.145\end{array}$ & 0.174 \\
\hline \multirow[t]{2}{*}{ Caregivers } & None & & & & 1 & & \\
\hline & Family/Neighbor & & & & 0.634 & $\begin{array}{l}0.348- \\
1.158\end{array}$ & 0.138 \\
\hline
\end{tabular}


ancome level: $1^{\text {st }}$ quantile (Medical aid beneficiaries), $2^{\text {nd }}$ quantile ( $1 \mathrm{st}-3^{\text {rd }}$ quantile), $3^{\text {rd }}$ quantile (4th- $5^{\text {th }}$ quantile), $4^{\text {th }}$ quantile $\left(6^{\text {th }}-8^{\text {th }}\right.$ quantile), $5^{\text {th }}$ quantile $\left(9^{\text {th }}-10^{\text {th }}\right.$ quantile)

${ }^{b}$ Activity Daily Limitation: Independent (score 13-19), partially dependent (score 20-26), fully dependent (score 27-39)

'Cognitive ability: Good (score 0-5), Bad (score 6-10)

dLTCS: Long-Term Care Service

※ facility (reference): non-user ( $\mathrm{HR}=3.910,95 \% \mathrm{Cl}=2.073-7.373)$, in-home $(\mathrm{HR}=2.862 .95 \% \mathrm{Cl}=1.512-$ 5.417)

Table 3. DID analysis of expansion of LTCS with dementia special grade 


\begin{tabular}{|c|c|c|c|c|}
\hline & & OR & $95 \% \mathrm{Cl}$ & p-value \\
\hline \multirow[t]{2}{*}{ Expansion of dementia special grade } & Before (-2013) & 1 & & \\
\hline & After (2014-) & 2.131 & $1.061-4.280$ & 0.034 \\
\hline \multirow[t]{2}{*}{ aLTCS } & Non-user & 1 & & \\
\hline & User & 0.296 & $0.183-0.478$ & $<0.001$ \\
\hline Interaction term & After expansion X Use & 1.589 & $0.667-3.788$ & 0.296 \\
\hline \multirow[t]{2}{*}{ Sex } & Male & 1 & & \\
\hline & Female & 0.418 & $0.290-0.603$ & $<0.001$ \\
\hline \multirow[t]{3}{*}{ Age } & $60-69$ & 1 & & \\
\hline & $70-79$ & 0.488 & $0.271-0.880$ & 0.017 \\
\hline & Over 80 & 0.430 & $0.237-0.781$ & 0.006 \\
\hline \multirow[t]{5}{*}{ bIncome level } & $5^{\text {th }}$ quantile & 1 & & \\
\hline & $4^{\text {th }}$ quantile & 1.122 & $0.675-1.866$ & 0.657 \\
\hline & $3^{\text {rd }}$ quantile & 1.041 & $0.530-2.042$ & 0.908 \\
\hline & $2^{\text {nd }}$ quantile & 1.283 & $0.766-2.150$ & 0.343 \\
\hline & $1^{\text {st }}$ quantile & 1.095 & $0.635-1.889$ & 0.744 \\
\hline \multirow[t]{3}{*}{${ }^{\mathrm{c}} \mathrm{ADL}$} & Independent & 1 & & \\
\hline & Partially dependent & 1.252 & $0.785-1.999$ & 0.346 \\
\hline & Fully dependent & 0.380 & $0.187-0.774$ & 0.008 \\
\hline \multirow[t]{2}{*}{${ }^{\mathrm{d} C o g n i t i v e ~ a b i l i t y ~}$} & Good & 1 & & \\
\hline & Bad & 0.824 & $0.527-1.288$ & 0.396 \\
\hline \multirow[t]{3}{*}{ Caregivers } & None & 1 & & \\
\hline & Family/Neighbor & 0.812 & $0.451-1.462$ & 0.488 \\
\hline & Nurse & 0.604 & $0.301-1.212$ & 0.156 \\
\hline
\end{tabular}

ancome level: $1^{\text {st }}$ quantile (Medical aid beneficiaries), $2^{\text {nd }}$ quantile ( 1 st- $3^{\text {rd }}$ quantile), $3^{\text {rd }}$ quantile (4th- $5^{\text {th }}$ quantile), $4^{\text {th }}$ quantile $\left(6^{\text {th }}-8^{\text {th }}\right.$ quantile), $5^{\text {th }}$ quantile $\left(9^{\text {th }}-10^{\text {th }}\right.$ quantile $)$

${ }^{b}$ Activity Daily Limitation: Independent (score 13-19), partially dependent (score 20-26), fully dependent (score 27-39) 
${ }^{\mathrm{C}}$ Cognitive ability: Good (score 0-5), Bad (score 6-10)

dLTCS: Long-Term Care Service

\section{Figures}

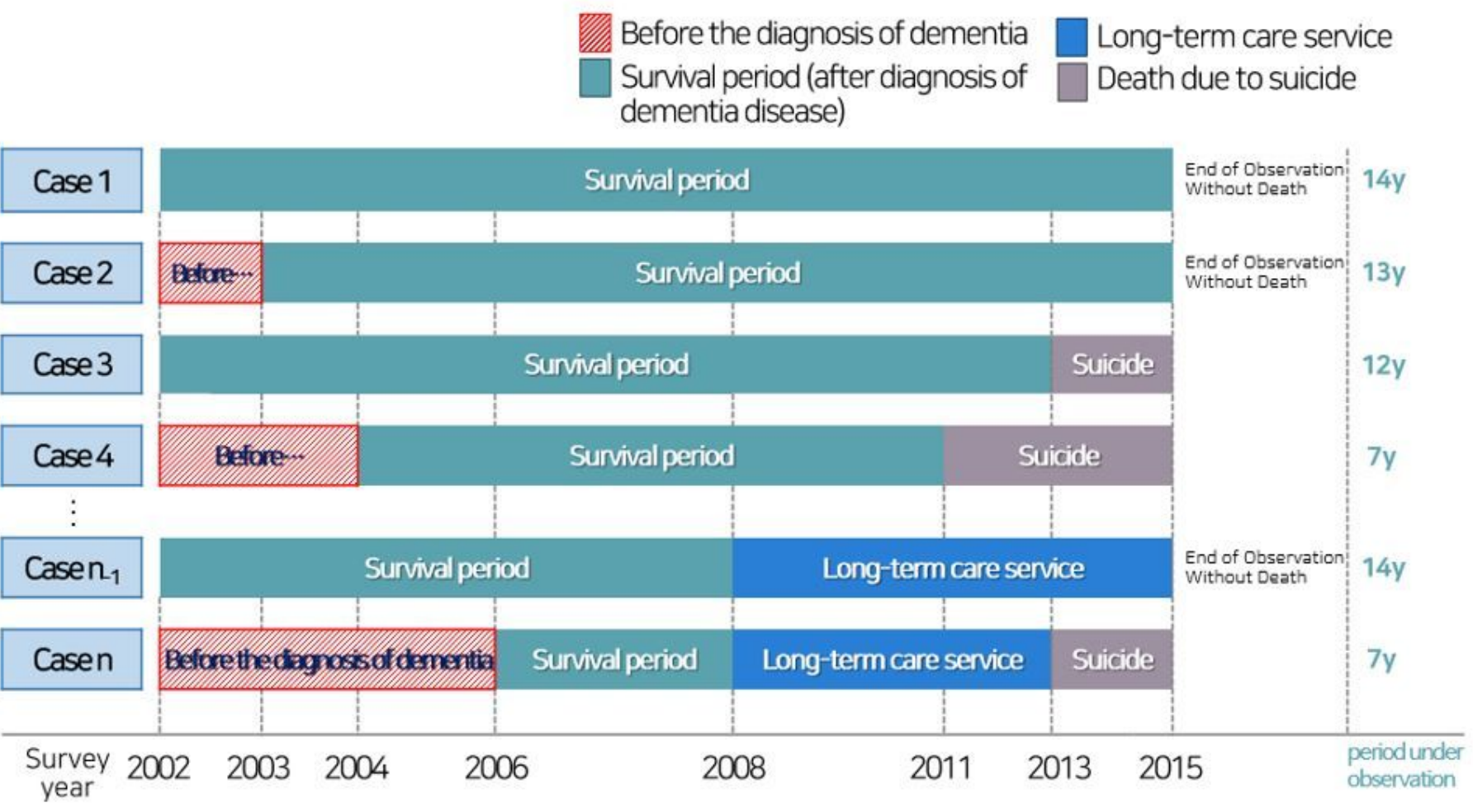

\section{Figure 1}

The structure of study sample 

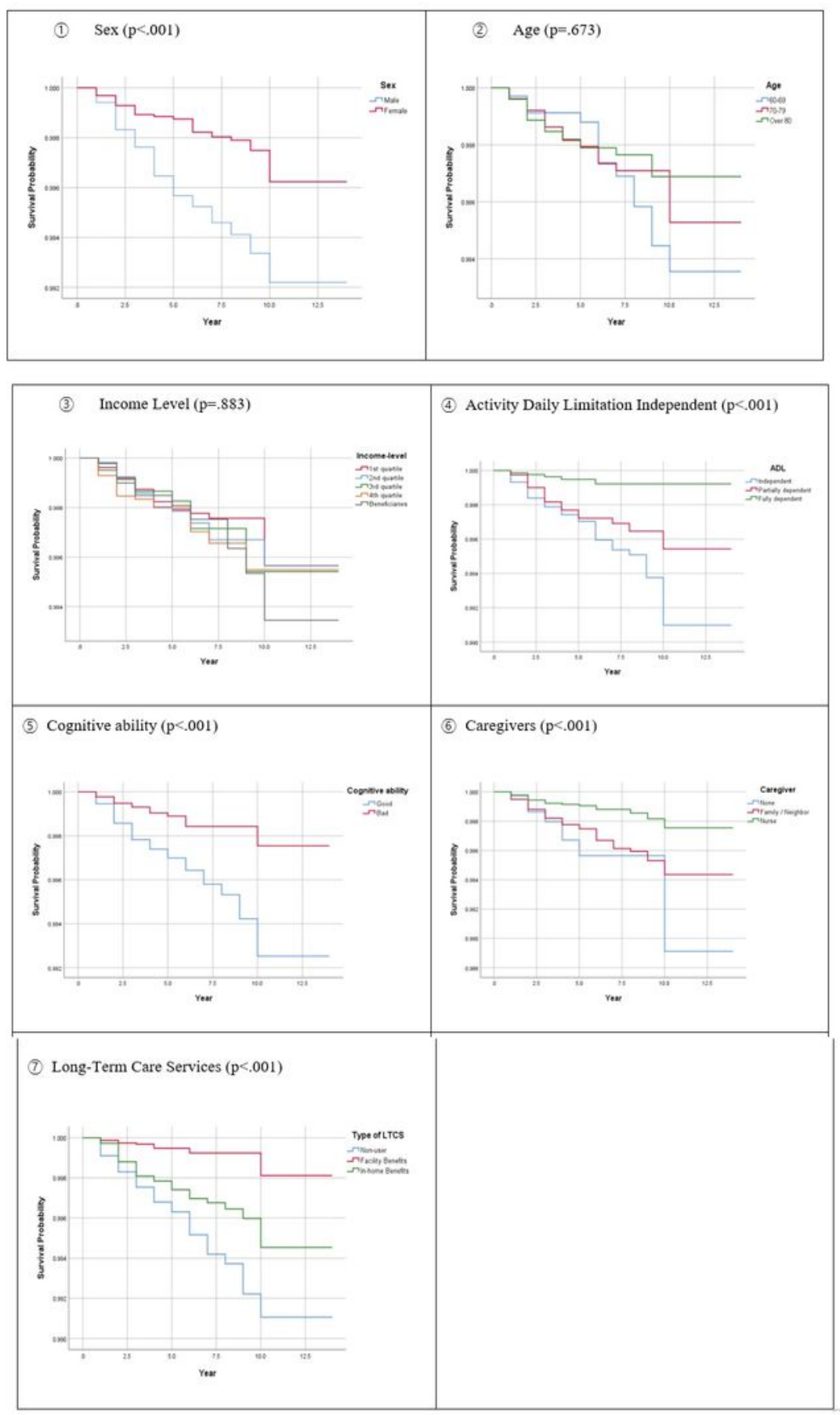

Figure 2

Suicide survival curves by influencing factors of the elderly with dementia 